\title{
Jornalismo Social: Os Desabafos e Desafios de Claras Norte-mineiras no Projeto da Economia de Francisco
}

\section{Cleidionice Pereira dos Santos}

Acadêmica do curso de Jornalismo das Faculdades Integradas do Norte de Minas - Funorte.

cleidionice.santos@soufunorte.com.br

\section{Elpídio Rodrigues da Rocha Neto}

Professor do curso de Jornalismo das Faculdades Integradas do Norte de Minas - Funorte.

elpidio.rodrigues@funorte.edu.br

\section{Resumo}

Este artigo aborda a problemática vivenciada por "Claras do Norte de Minas", que são mulheres de classe baixa, inspiradas no chamado do Papa, Economia de Francisco e Clara. Através das particularidades do jornalismo social, aquele que assume o discurso e as razões dos mais fracos e dos mais pobres, com uma perspectiva influente na narração dos conflitos. O papel social do jornalismo é chegar o mais próximo possível da verdade para transmitir ao público informações precisas e fundamentais. Além de fiscalizar o poder, cobrando, denunciando e exigindo punição aos responsáveis por desmandos e atos ilícitos. A grande reportagem propõe-se a trabalhar os acontecimentos numa profundidade contextual, possibilitando um mergulho nos fatos e oferece ao autor uma dose ponderável de liberdade para relatar . Economia de Francisco e Clara corresponde a um chamado do Papa Francisco, em maio de 2019, para acadêmicos e ativistas sociais repensarem juntos a economia global.

Palavras-Chave: Jornalismo Social; Grande Reportagem; Economia de Francisco e Clara; Claras norte-mineiras.

\section{Abstract}

This article addresses the problems experienced by "Claras do Norte de Minas", who are lower class women, inspired by the Pope's call, Francisco and Clara's Economy. Through the particularities of social journalism, that which assumes the discourse and reasons of the weakest and the poorest, with an influential perspective in the narration of conflicts. Journalism's social role is to get as close to the truth as possible in order to convey accurate and fundamental information to the public. In addition to overseeing power, demanding, denouncing and demanding punishment from those responsible for excesses and illegal acts. The great article proposes to work the events in a contextual depth, enabling a immersion in the facts and offering the author a considerable amount of freedom to report. Francisco and Clara's Economy 
corresponds to a call by Pope Francis, in May 2019, for academics and social activists to rethink the global economy together.

Keywords: Social Journalism; Great Report; Economy of Francisco and Clara; Claras norte-mineiras.

\section{INTRODUÇÃO}

$\mathrm{O}$ artigo apresentado tem como objetivo relatar a problemática vivenciada por mulheres (Claras) do Norte de Minas, relacionada à Economia de Francisco e Clara. Assim, através das particularidades do jornalismo social pretende-se cumprir os objetivos de compreender o processo de apuração dos fatos, pesquisar dados e documentos referentes à Economia de Francisco e Clara; e identificar e coletar os depoimentos de quatro Claras norte-mineiras.

Hoje, o impacto causado por uma notícia bem apurada não deve ser sentido apenas por aquele consumidor que tem o hábito de ler, assistir ou pesquisar por fatos e acontecimentos atualizados na televisão, jornal impresso, revista, rádio e internet. Tem que ir além e possuir uma linguagem capaz de atingir a todos e todas, tem que ser tocante a ponto de mudar, transformar uma realidade. Talvez, por isso, cumprir o papel do jornalista dentro dos preceitos éticos, apontando verdades e desfazendo injustiças, sempre foi e será um desafio. Não tem como negar que o jornalismo, independente da sua especificidade, se reinventa a cada dia para permanecer vivo - e é isso que o torna fascinante.

Para o bom jornalista, aquele que sabe abraçar a oportunidade, com criatividade, entusiasmo e autonomia, apresentar um trabalho de qualidade profissional é buscar o sucesso com ética e compromisso. No caso do profissional da área do jornalismo social, a luta é ainda mais instigante, principalmente, quando usa de gêneros jornalísticos, como a grande reportagem (que dá liberdade para levantar debates com temáticas atuais e relevantes), para abordar o crescimento da desigualdade social em todo planeta; esta realidade está incomodando lideranças mundiais como o Papa Francisco, que sentiu a necessidade de chamar a sociedade para se juntar ao debate titulado de Economia de Francisco e Clara.

O projeto Economia de Francisco corresponde a um chamado do Papa Francisco, em maio de 2019, para jovens acadêmicos, economistas, professores, pesquisadores e ativistas sociais repensarem juntos a economia global. Foi inspirado na Carta Encíclica Laudato Si, elaborada em 2015, e o nome é uma alusão a São Francisco de Assis; a proposta é pensar e construir uma economia mais justa, inclusiva e humanizada para reduzir a desigualdade social no planeta. $\mathrm{O}$ documento defende uma atitude "que nos ajude a estar unidos, a conhecer-nos uns aos outros, e que nos leve a estabelecer um 'pacto' para mudar a economia atual e atribuir uma alma à economia de amanhã" (ANEC, 2019).

“Claras norte mineiras” é uma alusão a Santa Clara de Assis (1193-1253). Que de acordo com Guimarães (2019) foi uma mulher muito à frente do seu tempo. De origem italiana, da cidade de Assis, Clara de Assis, nasceu de família nobre e recebeu 
esse nome após um profundo momento espiritual e inspirador da sua mãe, de que sua filha seria uma luz para o mundo. Terna, corajosa e preocupada com os pobres. A relação com as quatro mulheres, protagonistas da pesquisa, está na forma corajosa de encarar os desafios da vida.

Mas, o que tem a ver o debate levantado pelo Papa com as protagonistas deste projeto experimental? Qual a importância em ouvi-las e socializar o dito? O mundo, nas últimas décadas, tem vivido sob o modelo econômico neoliberal, que gera dificuldade social em níveis crescentes e estimula a concentração de renda e de poder. Neste contexto, a Economia de Francisco e Clara surge como ferramenta para a construção de modelos opostos ao que está vigente, numa tentativa de promover a igualdade e o respeito ao indivíduo e ao planeta. Assim, pode-se pensar em romper com a exploração gerada pela busca do capital, oferecendo uma opção mais sustentável e justa de convívio humano no planeta.

O uso das práticas jornalísticas de modo ético e profissional deu embasamento à elaboração da grande reportagem, que registrou a trajetória das Claras norte-mineiras, revelando as conquistas e os desafios que elas enfrentam no dia a dia. Desta forma, admite-se que o trabalho vai estimular discussões e pode conscientizar a sociedade sobre outras opções econômicas além do status quo dominante.

\section{MATERIAIS E MÉTODOS}

Para a realização do projeto, o estudo foi executado por meio de uma abordagem exploratória, qualitativa e descritiva, que foi desenvolvida por meio de pesquisa bibliográfica e entrevistas com personagens relacionadas ao tema pesquisado. Em seguida, as informações coletadas foram organizadas para a elaboração de um produto jornalístico, a grande reportagem.

Gil (2008) diz que as pesquisas exploratórias têm como objetivo reestruturar conceitos e ideias, concentrando-se em problemas mais precisos e hipóteses estruturadas para estudos decorrentes; apresentam menor rigidez no planejamento e utilizam levantamentos bibliográficos e documentais, entrevistas não padronizadas e estudos de caso. A pesquisa bibliográfica se fundamentou na coleta de dados e informações teóricas que contribuíram para o resultado do projeto.

A pesquisa qualitativa se desenvolve em cinco características básicas: ambiente natural, dados descritivos, cuidado com os dados, preocupação com o significado e processo de análise indutivo. Além disso, admite-se que a qualidade (e não a quantidade) é mais importante na abordagem qualitativa - que permite um aprofundamento na realidade social, buscando explicar o porquê dos fatos (Pereira, et al., 2018).

A fim de alcançar os objetivos propostos, as entrevistas para coletas de dados foram individuais, porém, por meio remoto (conforme parecer do Centro de Pesquisas, devido à pandemia do novo coronavírus). A pesquisa descritiva permitiu ao pesquisador identificar as características de certa população ou fenômeno, estabelecendo relações entre as variáveis; desta forma, pode-se responder a questão do problema pesquisado (Júnior, 2017). 
A população deste estudo foi constituída por personagens femininas da região Norte de Minas Gerais e pesquisadores ligados ao tema proposto. A escolha das entrevistadas se relaciona com a Economia de Francisco e Clara, identificando mulheres em situação extrema por causa da desigualdade social. As entrevistas concedidas pelas fontes foram empregadas na produção de uma grande reportagem, o produto jornalístico do projeto.

Com a pesquisa em mãos e os dados obtidos, mediante coleta bibliográfica, pôdese apurar e organizar as informações sobre o jornalismo social, grande reportagem, Economia de Francisco e Clara e Claras norte-mineiras. Essa etapa incluiu a avaliação dos dados por meio de materiais textuais, fotográficos e audiovisuais dos personagens, a gravação de entrevistas e a produção e seleção das imagens que foram usadas para compor o conteúdo da grande reportagem.

O projeto titulado Jornalismo social: os desabafos e desafios de Claras norte-mineiras no projeto da Economia de Francisco foi encaminhado ao Comitê de Ética das Faculdades Integradas do Norte de Minas (CEP-FUNORTE) para apreciação em 13/07/2020 e o parecer de aprovação foi emitido no dia 21/08/2020, protocolado pelo $n^{\circ}: 4.228 .172$.

\section{JORNALISMO, JORNALISMO SOCIAL E O SEU PAPEL}

O jornalismo é uma atividade desafiadora e encantadora, que deve servir à sociedade para que as pessoas possam falar e serem ouvidas; para muitos, como Samuel Wainer, é "uma razão de viver". Medeiros (2009) garante que Wainer viveu uma experiência humana completa ao cumprir uma trajetória que lhe permitiu conhecer a ascensão, a glória e a queda no "universo jornalístico". A ética, que representa um conjunto de valores fundamentais, deve ser o ensejo, "a razão de ser” da ação jornalística, que se concentra no direito do outro: seja cultural, cívico, político ou social do cidadão. Sendo assim, o jornalista não pode falsear a linguagem e nem fraudar os fatos (Chaparro 2017).

Dentre as várias reflexões teóricas acerca da história do jornalismo brasileiro, é preciso destacar a ação do intelectual idealista, defensor da liberdade e do progresso, Hipólito José da Costa (1774-1823), que, segundo Oliveira (2017), em 1808, com a chegada da família real portuguesa à colônia, cria o primeiro periódico do Brasil: O Correio Braziliense, em Londres. De forma clandestina, os fascículos escritos por Costa chegavam ao país apoiando e dando cobertura a revoltas internas, como os acontecimentos que levaram à independência do Brasil. Dessa forma, durante os 14 anos de circulação do jornal, Hipólito da Costa deixou a sua contribuição ao jornalismo brasileiro, com uma trajetória histórica, marcada por iniciativas revolucionárias, consagrando-se como o patrono da imprensa nacional (Oliveira, 2017).

Medeiros (2009) informa que a imprensa surgiu no Brasil em 1808, com o diário oficial criado por Dom João VI e denominado Gazeta do Rio de Janeiro. Hohlfeldt e Valles (2008) afirmam que a primeira grande fase da imprensa brasileira, que fez o jornalismo se desenvolver rapidamente, foi entre 1830 e 1950. A partir desta época são muitas as definições conceituais dadas ao jornalismo por diversos pensadores, como 
Luiz Beltrão, Carlos Chaparro, Edivaldo Lima. De acordo com Brito (2018), Beltrão vê o jornalismo como a informação de fatos correntes, adequadamente interpretados e transmitidos regularmente à sociedade, para difundir conhecimentos, orientar a opinião pública e promover o bem comum. Para Lima (2009), o jornalismo tem a função de informar, explicar e orientar.

Chaparro (2017) defende que o jornalismo se tornou o espaço público dos confrontos discursivos e não tem ninguém que não utiliza o jornalismo, seja jornalista, leitor, telespectador, ouvinte, internauta ou fonte. Atualmente, o mundo vive a "era" em que a notícia verdadeira bate de frente com a notícia falsa - e o país possui um governo que não oferece segurança ao profissional de imprensa; ao contrário, representa risco eminente de acordo com as estatísticas levantadas. Segundo Franco (2020), o ano de 2019 teve um aumento de 54\% nos ataques contra jornalistas. Do total de 208 ocorrências registradas, 121 casos foram abertamente ocasionados pelo presidente Jair Bolsonaro, dado que pode ser consultado em relatórios divulgados pela Federação Nacional dos Jornalistas (Fenaj).

A era das fake news tem criado situações desafiadoras para o profissional sério de comunicação, mas, se é fake não é notícia. É nisso que Portello e Brites (2018) acreditam, afirmando que, para existir, a notícia precisa ser verdadeira, verificável, checada e chancelada por um jornalista; as fake news são notícias distorcidas, erradas ou mal apuradas. O papel social do jornalismo é chegar o mais próximo possível da verdade para transmitir ao público as informações precisas e fundamentais para a convivência entre as pessoas e, também, fiscalizar o poder, cobrando, denunciando e exigindo punição aos responsáveis por desmandos e atos ilícitos (Portello; Brites, 2018).

No jornalismo, segundo Hohlfeldt e Valles (2008), os aspectos de divulgação de um fato são informação, interpretação e opinião; esses aspectos se estruturaram em três categorias: informativo (noticia, apenas narra os fatos); opinativo (o ponto de vista do jornalista fica claro em textos como editoriais, artigos e crônicas); e interpretativo (contextualização do fato a partir do desdobramento e da apuração dos dados). Eles ressaltam, ainda, que a tecnologia é a grande aliada do repórter quando contribui para a investigação, amplia o acesso a informações remotas e permite a organização sistemática de um número expressivo de dados. Para Chaparro (2017), o jornalismo se constrói com informação e opinião e é uma profissão cada vez mais relevante, principalmente quando assume a abordagem crítica e consistente das questões sociais.

O que é jornalismo social?

Leite (2013) argumenta que definir o jornalismo social é muito difícil, pois a bibliografia sobre o assunto é quase nula. Porém, a autora constrói o conceito de uma nova modalidade do jornalismo que, por meio da linguagem, da busca de soluções, do relacionamento com o público e da preocupação com o desenvolvimento econômico, pretende sintonizar o elo social aos elos econômicos e políticos, incorporando os indivíduos de forma participativa na abordagem dos diferentes temas e assuntos (Leite, 2013).

Figueiredo (2015) destaca que o jornalismo social tem a sua importância específica e não deve ser confundido, por exemplo, com o jornalismo cidadão, que é aquele que 
qualquer cidadão pode exercer. Para o autor, a diferença entre um jornalista amador e um profissional pode ser tão grande quanto a existente entre um profissional consciente e preparado e um esforçado amador que se interessa por um determinado assunto. $\mathrm{O}$ talento jornalístico é reforçado e construído com modelos, técnicas e ferramentas que o jornalista profissional sabe dominar e que o colocam a uma distância ainda maior do amador - concluí Figueiredo (2015).

Chaparro (2004) declara que a responsabilidade e o comprometimento da parte de um profissional é muito maior perante a sociedade e afirma que as demandas sociais exigem um jornalismo cada vez mais atento e esclarecedor da atualidade. Assim, o jornalismo que assume o discurso e as razões dos mais fracos e dos mais pobres, com uma perspectiva influente na narração dos conflitos, deveria ser chamado de social. Aos olhos do autor, o mundo é que muda o jornalismo, não o contrário; para ele, o jornalismo se transformou em uma linguagem social que pode ser usada pelo comunicador capacitado para construir um trabalho apurado e humanizado, ganhando espaço e identidade nas mídias e, ao mesmo tempo, atuando como um agente transformador na sociedade. Essa perspectiva reforça a ideia de um jornalismo verdadeiramente social (Chaparro, 2017).

\section{GRANDE REPORTAGEM}

Segundo Silva e Baltazar (2013), um determinado fato ganha força jornalística no momento em que se aproxima da especificidade, quando revela características somente suas e marcadas de singularidade. Para as autoras, a notícia é a base do jornalismo, mas é a reportagem que pode ser considerada o grande momento jornalístico; portanto, fazer um jornalismo diário contextualizado é um desafio para os jornalistas, porque precisam superar a correria do dia a dia, o número de profissionais reduzidos nas redações e a busca por furo pelas empresas de comunicação. De acordo com Santos (2009), o jornalismo é a linguagem dos conflitos e a reportagem é um relato que se dá por descobertas, apuração e explicações associadas ao interesse público e à defesa da democracia.

Silva e Baltazar (2013) dizem que a origem da reportagem, no Brasil, deve-se a João Paulo Alberto Coelho Barreto, ao escrever matérias retratando a cidade do Rio de Janeiro, entre 1898 e 1899, no jornal Cidade do Rio. O repórter se tornou conhecido como João do Rio, alcançou o sucesso e passou a fazer parte do time d' $A$ Gazeta de Notícias. Em 1904, iniciou uma série de textos sobre as religiões cariocas, que denominou como reportagens. Para produzir as matérias, o repórter foi até as ruas, conversou com as pessoas, visitou templos, igrejas, seitas e cultos.

No pensamento de Chaparro (2017), a boa reportagem é sempre resultado da existência e da relação solidária, bem articulada entre três pré-condições: um bom repórter, um bom assunto e um bom motivo. Segundo Lima (2009), a reportagem é um gênero jornalístico privilegiado, tem suas regras próprias e, através dela, se faz História. Marques de Melo (in Lima, 2009) defende que a reportagem é o relato ampliado de um acontecimento que já repercutiu na sociedade e produziu alterações 
sentidas no jornalismo. Klautau, Künsch e Carraro (2018) acreditam que a reportagem que tenta abranger a realidade em profundidade precisa ouvir as múltiplas vozes envolvidas no fato, fazendo emergir múltiplos sentidos e enriquecendo a narrativa.

Medina (in Lima, 2009) enxerga a reportagem como o gênero jornalístico que melhor atende às aspirações da democracia contemporânea, estruturando-se numa narrativa de ampliação dos fatos. Lima (2009) informa que a reportagem se desenvolveu a partir dos anos 1920, atrelada a veículos de comunicação periódica e fundamentada na expansão do relato simples e raso da notícia para uma dimensão contextual e com maior amplitude dos personagens envolvidos. São características importantes deste gênero jornalístico: predominância da forma narrativa, humanização do relato, texto de natureza impressionista e objetividade dos fatos narrados (Lage in Lima, 2009).

De acordo com Silva e Baltazar (2013), a grande reportagem propõe-se a trabalhar os acontecimentos numa profundidade contextual, que possibilita um mergulho de fôlego nos fatos e oferece ao seu autor uma dose ponderável de liberdade para superar os padrões e fórmulas convencionais do tratamento da notícia. Para Lima (2009), a grande reportagem é aquela que possibilita um mergulho de fôlego nos acontecimentos e em seu contexto, oferecendo ao autor certa liberdade para fugir dos grilhões impostos pela forma convencional de produzir jornalismo. Ou seja, trata-se de uma abordagem multiangular para a compreensão da realidade.

Araújo e Luindia (2011) explicam as três etapas fundamentais para a prática da grande reportagem: primeiro, a pesquisa e validação dos dados com a seleção de documentos e bibliografia para a construção consistente e coerente do texto; em seguida, a realização da entrevista na qual os personagens ganham voz e relevância, produzindo um relato humanizado; por último, a construção do produto em que o jornalista busca um aprofundamento contextual, conceitual e ético.

Após tudo que foi exposto sobre a grande reportagem, fica evidente, segundo Lima (2009, p. 175), que o jornalista "precisa partir a campo, ver, sentir, cheirar, apalpar, ouvir os ambientes por onde circulam seus personagens" para produzir uma matéria em profundidade sobre os fatos que incomodam ou merecem atenção especial. E foi o incômodo diante da realidade difícil das mulheres de baixa renda, do Norte de Minas, que gerou o interesse em pesquisar o jornalismo social para fundamentar a abordagem sobre a Economia de Francisco, destacando o papel das Claras nortemineiras no contexto desta renovação da economia proposta pelo Papa Francisco.

\section{ECONOMIA DE FRANCISCO E CLARA}

De acordo com Stedile (2015), o cardeal argentino Jorge Mario Bergoglio, em 13 de março de 2013, tornou-se o primeiro papa latino-americano e escolheu o nome Francisco, porque pensou nos pobres, no combate à fome e ao desemprego e no enfrentamento aos problemas das guerras e das migrações. $\mathrm{O}$ autor diz que, desde o segundo semestre de 2013, o Papa Francisco deu sinais de que queria estabelecer articulações com os movimentos populares de todo o mundo. Em outubro de 2014, o Vaticano organizou um encontro com mais de 180 lideranças sociais de todo mundo; o 
segundo, com participação de 1.500 representantes de 40 países, aconteceu na Bolívia, em julho de 2015. Em seu discurso, na abertura do evento boliviano, o pontífice afirmou que terra, teto e trabalho são direitos sagrados do ser humano e defendeu três linhas de ação do seu papado: colocar a economia a serviço dos povos, unir os povos no caminho da paz e da justiça e defender a Mãe Terra. O terceiro encontro com o Papa Francisco estava agendado para março de 2020, em assis (itália), mas foi suspenso devido à pandemia do coronavírus (Stedile, 2015).

No Brasil, a Articulação Brasileira pela Economia de Francisco e Clara - Abecofranc - foi criada para estruturar a proposta do Papa no país e destacou nas discussões a figura de Santa Clara de Assis, que defendia a construção do diálogo entre todos os povos. O objetivo da associação é defender "uma economia que, em princípio, deve servir para vivermos melhor, e não para estarmos ao seu serviço. Uma economia que se proponha ao bem comum, seja socialmente justa e ambientalmente sustentável" (ABFC, 2020).

De acordo com as informações da Associação Nacional de Educação Católica (ANEC), cidades de todos os estados brasileiros se organizaram para discutir e aprovar propostas de ação que seriam apresentadas em Assis - obviamente, os encontros foram realizados antes do isolamento social, provocado pelo coronavírus. Em Belo Horizonte (MG), os articuladores, em parceria com a PUC Minas e organizações da sociedade civil, discutiram perspectivas e ideias por meio de mesas redondas, painéis, seminários e debates. Montes Claros sediou, em novembro de 2019, o primeiro debate norte-mineiro organizado pela Articulação Norte Mineira pela Economia de Francisco e Clara. Além do palestrante Rudá Ricci, participaram 32 representantes de entidades sociais (acadêmicos, docentes, trabalhadores rurais, ambientalistas, lideranças populares, etc.) de oito cidades da região (ANEC, 2019).

O chamado do Papa despertou a curiosidade e criatividade de estudiosos em todo o mundo, como o economista e escritor Ladislau Dowbor (2017), que defende a reconstrução dos preceitos econômicos atuais - e afirma que a desigualdade é fruto de um sistema institucionalizado que favorece a supremacia dos ricos sobre os mais pobres. Dowbor acredita que o objetivo geral da economia é (ou, pelo menos, deveria ser) promover o bem-estar das pessoas, sem colocar em risco ou destruir o futuro das próximas gerações. Para ele, esse bem-estar não se resume a um salário mínimo, à renda que se recebe pelo trabalho. A renda tem um papel importante, porque permite ao trabalhador comprar remédios e pagar o aluguel, mas, quase tão importante é o chamado salário indireto, o acesso ao consumo coletivo que se torna possível quando o país dispõe de sistemas públicos de saúde, educação, cultura, segurança, um ambiente sem poluição e semelhantes (Dowbor, 2020).

Articulador do projeto, o sociólogo e cientista político Rudá Ricci (2020) traz uma reflexão importante para o debate: atualmente não se observam questionamentos contundentes em relação à existência e ao crescimento das fortunas bilionárias no mundo; são pessoas que usufruem de uma condição de vida que vai muito além do que se considera necessário e, para manterem os seus privilégios, não hesitam em investir na devastação da natureza e na decadência das relações humanas e coletivas. 
Para o sociólogo, é estranho que à beira do abismo a humanidade acredite que o melhor é dar um passo à frente (Ricci, 2020). Já o jornalista e antropólogo Frei Betto (2020) acredita que o aumento da desigualdade brasileira ocorre porque os governos não fizeram reformas estruturadas e básicas, como a agrária e a tributária. Ambos se encontram e colaboram no apoio à Economia de Francisco e Clara.

De acordo com a Articulação Brasileira pela Economia de Francisco e Clara, o projeto proposto e estimulado pelo Papa oferece uma nova visão para a economia do século XXI, reforçando a união e a comunhão dos indivíduos em defesa de ideais coletivos, éticos e de melhoria para a maioria da população - o que pode ser resumido numa ação em que: a "opção preferencial é pelos pobres, pelos excluídos, pelos desvalidos. Pelo pão, pelo trabalho, pelo teto e pela terra, pelo planeta. Pelo que é justo" (ABFC, 2020).

\section{CLARAS NORTE-MINEIRAS}

A assistente social Sônia Gomes de Oliveira, com pós-graduação em Fé e Política, pela PUC-RJ, atua junto a 18 pastorais sociais na Arquidiocese de Montes Claros e atende a grupos sociais de mulheres catadoras, população em situação de rua e pessoas em risco de conflito. Oliveira fez um levantamento de dados durante a pandemia, de maio a julho de 2020 , somando 9.500 visitas, no qual foi constatado "que a grande maioria das famílias é chefiada por mulheres, quase todas desempregadas e passando por necessidades. É uma realidade duríssima” (Oliveira, 2020).

Pode parecer óbvio, mas este dado confirma o que disseram as Claras, protagonistas desta pesquisa, as quais se encontram espalhadas por diversos cenários do Norte de Minas, enfrentando desafios para garantir o mínimo (saúde, educação, alimentação, etc.) necessário à sobrevivência. "O meu sonho é ter uma vida melhor e ter um salário fixo. A gente ganha muito pouco; queremos condições melhores nas nossas casas e nos sustentar melhor. Precisamos de muitas coisas, até de ajuda de outras pessoas para sobrevivermos", diz a catadora Maria do Socorro Guimarães Soares (Oliveira, 2020).

Soares, 60 anos, mãe de cinco filhos, trabalhava como doméstica e começou na reciclagem sozinha. Logo teve a percepção de que se o trabalho fosse executado em conjunto poderia ser muito melhor; além de agregar forças, ela lutou por essa organização e hoje é presidente da associação de catadores na maior cidade do Norte de Minas. Apesar das conquistas, declara que vive no limite o tempo todo, quando enfrenta situações em que tem de escolher entre duas prioridades - como comprar um chinelo ou um pão - porque o dinheiro não dá para as duas (Soares, 2020).

"Meu sonho é ter um salário digno, que desse para adquirir minha casa, e aprender ler", desabafa, em entrevista, Ana Maria Rodrigues de Aquino, de 37 anos, moradora da cidade de Jaíba (MG). Contratada há menos de três meses como colhedora de frutas, trabalho que vinha prestando como diarista desde 2016, Aquino revela que é um desafio muito grande, pois sai de casa na madrugada e retorna já no início da noite, enfrentando sol, chuva, comida gelada e ganhando pouco para pagar o aluguel e as contas de água e luz. As dificuldades são pesadas, porque ela está sozinha como 
chefe de família: "tenho duas filhas e elas têm problemas de saúde e dependem de mim. O pai nunca quis nem fazer o registro, muito menos ajudar financeiramente" (Aquino, 2020).

"A subsistência vem do que fazemos, não temos salários e nosso sustento vem unicamente da agricultura familiar", declara a quilombola Dermira Ferreira Borges, 54 anos, que trabalha na educação, numa escola do Quilombo da Lapinha, comunidade marcada pela luta a favor dos direitos de seus moradores e localizada em Matias Cardoso (MG). De acordo com Borges, os principais desafios estão na busca do direito pelos territórios, por sobrevivência, por manter sua cultura, suas raízes e seu modo de vida. "Essa é nossa luta: a gente vem há muito tempo lutando, não só pelo território, mas também pelas águas do rio São Francisco, que é a fonte da nossa vida aqui, na comunidade, e para todos os ribeirinhos. Estamos lutando há muito tempo para não deixar o rio acabar", conclui a quilombola (Borges, 2020).

Conhecida como Tia Teu, a quilombola Elzina Fernando de Souza informa que só teve oportunidade de estudar até a terceira série do ensino fundamental, mas conseguiu resgatar a cultura local, lutar pelos direitos da sua comunidade e conquistar espaço de atuação na região. Aos 69 anos, mãe de cinco filhos (só um deles está vivo) e avó de uma menina que enfrenta um câncer grave, ela declara que cansou de cobrar uma melhor atuação das autoridades e lançou-se como candidata a uma vaga no legislativo da cidade para representar melhor a sua gente. "O negro não é burro, o negro pode ser ignorante, mas burro não; eu sou ignorante em cima dos meus diretos. $\mathrm{O}$ preconceito dói - e são muitos, dos mais variáveis possíveis, principalmente o do racismo, mas não abaixo a cabeça”, diz Souza (Souza, 2020).

Dando embasamento aos depoimentos anteriores, a economista e feminista Isabela Rosangela Ferreira, de 31 anos, relata que, por ser mulher e negra, enxerga-se na luta por justiça social desde que se entendeu por indivíduo e esse desejo cresceu ainda mais dentro da academia. Segundo ela, as mulheres, principalmente as negras e pobres, são vistas como "sobreviventes que buscam, com muita persistência e esforço, o seu lugar dentro do mercado de trabalho, seja formal ou informal, para se manterem. Vivem uma luta árdua. Tudo isso devido à falta de políticas públicas, à desigualdade social, ao nível elevado de pobreza, etc.” (Ferreira, 2020).

Ferreira está entre os 500 brasileiros escolhidos pelo Vaticano para participar do debate mundial sobre a Economia de Francisco e Clara, com os representantes de outros 45 países, em Assis, sem data determinada, devido à crise sanitária que vive o mundo. Para ela, o encontro vai "debater uma nova economia para o futuro, aquela que inclui e não exclui a população. Esse chamado será um marco na história do planeta com a união de vários povos que vão cheios de ideias e de sonhos para transformá-los em ações praticáveis" (Ferreira, 2020).

O cientista político e coordenador nacional dos debates nos projetos Economia de Francisco e Clara e Pacto Global pela Educação no Brasil, Rudá Ricci (entrevista, 2020), enfatiza a relevância do chamado do Papa para discutir e "re-almar a economia mundial, ou seja, para pensar um novo modelo econômico que surge como uma esperança"; especialmente em situações como as das Claras norte-mineiras, que 
sabem o preço que pagam por serem mulheres, pobres, de baixa renda e negras. Para a professora e economista, Luciene Rodrigues, autora de vários trabalhos desenvolvidos a favor de uma economia mais justa e alinhados à proposta do Papa Francisco, "os dados de desemprego, especificamente agora, na pandemia, afetam muito mais as mulheres pretas que os homens. Não basta mais uma luta só por direito, ela tem que ser efetiva e concreta" (Rodrigues, 2020).

A grande reportagem (GR) titulada Os desabafos e desafios de Claras norte-mineiras ligadas à Economia de Francisco e Clara, produto comunicacional associado a este artigo científico, contou com as técnicas da investigação jornalística para a apuração e relato dos fatos. A GR foi impressa com 16 páginas, em preto e branco, no formato tabloide. O designer gráfico foi organizado por Luana Nicoletti, conforme as indicações da acadêmica Cleidionice Pereira dos Santos, baseando-se no layout de jornais atuais e nas orientações acadêmicas das disciplinas do curso. Na diagramação, buscou-se a qualidade visual com equilíbrio entre textos e fotos. $\mathrm{O}$ corpo principal do texto das matérias é 10, com a fonte Times New Roman também para box e legendas. As ilustrações do produto foram estruturadas com as fotos dos entrevistados e imagens que lembram os temas abordados. Identificados por títulos próprios, a matéria principal e os quatro depoimentos das Claras compõem o conjunto da grande reportagem, trabalhando com a humanização dos relatos das personagens e o estímulo a uma reflexão crítica e conscientizadora dos leitores.

\section{CONSIDERAÇÕES FINAIS}

Entende-se que o jornalismo social tem uma importância relevante junto à sociedade e pode ser incisivo e atuante no sentido de dar voz e vez às Claras nortemineiras. É necessário oferecer ao público uma visão mais apurada e crítica sobre o que acontece revelando as vozes daqueles (as) que muitas vezes estão inviabilizados diante dos interesses financeiros e políticos dos veículos de comunicação, alinhados ao pensamento mais conservador. Em contraponto a essa "manutenção do status quo", o jornalista social assume um papel de relevo ao registrar outras histórias de vida, geralmente à margem do sistema, e estimular o conhecimento e a conscientização dos leitores, telespectadores, ouvintes e internautas.

As entrevistas coletadas neste projeto experimental mostram as realidades de quatro mulheres que lutam pela sobrevivência e por melhores condições de vida: são personagens que vendem sua força de trabalho por pequenos rendimentos e, muitas vezes, só têm acesso ao almoço de cada dia; que enfrentam o racismo e o preconceito por serem mulheres negras; que se sustentam com a coleta e reciclagem do que, para muitos membros da sociedade, é lixo ou descartável; enfim, são Claras norte-mineiras que encontram forças para garantir a sua existência batalhando ainda pela sua família, comunidade e cultura local. Neste contexto, o projeto da Economia de Francisco e Clara tem importante destaque pela proposta de humanização da atividade econômica, respeito à dignidade humana e ao meio ambiente e defesa da melhoria de vida para os menos favorecidos e invisíveis diante dos interesses das 
grandes corporações financeiras.

A apuração realizada para sistematizar dados preliminares, reunir falas de personagens e, dentro das possibilidades jornalísticas, mostrar os depoimentos das Claras do Norte de Minas Gerais, produziu, neste trabalho de conclusão de curso, um artigo e uma grande reportagem que podem auxiliar em futuras pesquisas acadêmicas. Assim, espera-se que a grande reportagem estimule a divulgação e o apoio às propostas do Papa Francisco, catalisando alternativas e ações possíveis e cabíveis para a melhoria da situação social da atualidade.

Artigo recebido em 14 de maio de 2021 e aprovado para publicação em 05 de julho de 2021

\section{REFERÊNCIAS}

ANEC - Associação Nacional de Educação Católica. Economia de Francisco e Clara. 2019. Disponível em: <https://anec.org.br/acao/economia-de-francisco-eclara/>. Acesso em 02/04/20.

ABFC - Articulação Brasileira pela Economia de Francisco. Carta de Clara e Francisco. 2020. Disponível em: <https://ecofranbr.org/>. Acesso em: 11/06/20.

AQUINO, A. M. R. Entrevista remota realizada por Cleidionice Pereira dos Santos em 16 de outubro de 2020, em Montes Claros (MG).

ARAÚJO, C. N.; LUINDIA, L. E. A. O desafio da grande reportagem: a teoria, a técnica e a prática como elementos constituintes do trabalho monográfico em jornalismo. 2011. Disponível em: <https://www.researchgate.net/ publication/254256825_O_desafio_da_grande_reportagem>.Acesso em: 27/09/20. BETTO, F. O diabo na corte: leitura crítica do Brasil atual. 2020.

Disponível em: <https://books.google.com.br/books?id=HQfaDwAAQBAJ\&prin tsec=>. Acesso em: 11/06/20.

BORGES, D. F. Entrevista remota realizada por Cleidionice Pereira dos Santos em 16 de outubro de 2020, em Montes Claros (MG).

BRITO, N. C. R. Luiz Beltrão e os movimentos iniciais da pesquisa em jornalismo no Brasil. Pauta Geral - Estudos em Jornalismo, v. 5, n. 2, p. 24-40, dez. 2018. Disponível em: <https://www.revistas2.uepg.br/index.php/pauta/article/view/12306>. Acesso em: 09/04/20.

CAMPOS, P. C. A reportagem. 2002. Disponível em: <http://www. observatoriodaimprensa.com.br/primeiras-edicoes/a-reportagem/>. Acesso em 27/03/20.

CHAPARRO, C. M. O xis da questão. 2004. Disponível em: < http://www. observatoriodaimprensa.com.br/jornal-de-debates/carlos-chaparro-25846/>. Acesso em: 04/04/20.

Jornalismo sempre em transformação. 2017. Disponível em: 
<https://www20.opovo.com.br/app/opovo/paginasazuis/2017/01/09/ noticiasjornalpaginasazuis,3678622/jornalismo-sempre-em-transformacao.shtml >. Acesso em: 05/04/20.

DOWBOR, L.A era do capitalismo improdutivo e como superá-la. 2017. Disponível em: <https://dowbor.org/2017/08/antonio-martins-a-era-do-capital-improdutivoe-como-supera-la-agosto-2017-2p.html/>. Acesso em: 10/04/20.

O capitalismo se desloca: novas arquiteturas sociais. 2020. Disponível em: $<\mathrm{https}$ //dowbor.org/2020/05/debate-livro-novo-o-capitalismo-se-desloca-novasarquiteturas-sociais-ladislau-dowbor-e-antonio-martins-edicoes-sesc-26-05-16h. $\mathrm{html} />$. Acesso em: 10/06/20.

FERREIRA, I. R. Entrevista remota realizada por Cleidionice Pereira dos Santos em 22 de outubro de 2020, em Montes Claros (MG).

FIGUEIREDO, A. D. A descoberta do jornalismo de nova geração. 2015. Disponível em: $<$ https://www.researchgate.net/profile/Antonio_Dias_de_Figueiredo $>$. Acesso em: 28/09/20.

FRANCO, A. Violência contra jornalistas aumenta 54\% em 2019. 2020. Disponível em: <https://fenaj.org.br/violencia-contra-jornalistas-aumenta-54-em-2019/>. Acesso em $30 / 03 / 20$.

GIL, A. C. Métodos e técnicas de pesquisa social. $6^{\circ}$. ed. São Paulo: Atlas, 2008. GUIMARÃES, A. Clara de Assis: terna e corajosa. 2019. Disponível em: https:// franciscanos.org.br/ Acesso em: 30/06/21

HOHLFELDT, A. VALLES, R. R. Conceito e história do jornalismo brasileiro na Revista de Comunicação. Porto Alegre (RS): EdiPUCRS, 2008. Disponível em: <https://bibliodigital.unijui.edu.br:8443/xmlui/bitstream/handle/>. Acesso em: 30/08/20.

JÚNIOR, E. L.O. Pesquisa científica na graduação: um estudo das vertentes temáticas e metodológicas dos trabalhos de conclusão de curso. 2017. Disponível em: <https://repositorio.ufu.br/handle/123456789/20939>. Acesso em: 07/05/20.

KLAUTAU, C. M. KÜNSCH, D. CARRARO, R. A reportagem jornalística e a compreensão como método: um estudo da série "Um Mundo de Muros", da Folha de S. Paulo. 2018. Disponível em: <https://portalintercom.org.br/anais/nacional2018/ resumos/R13-1089-1.pdf>. Acesso em: 28/09/20.

LEITE, J. F. P. Jornalismo social em Portugal - estudo de caso da Revista Cais. 2013. Disponível em: <https://hdl.handle.net/10216/68691>. Acesso em: 28/09/20. LIMA, E. P. Páginas ampliadas: o livro-reportagem como extensão do jornalismo e da literatura. 4. ed. Barueri (SP): Manole, 2009.

MEDEIROS, B. A rotativa parou! Os últimos dias da Última Hora de Samuel Wainer. Rio de Janeiro: Civilização Brasileira, 2009.

OLIVEIRA, M. F. Hipólito José da Costa e as ideias econômicas d'O Correio Braziliense. Intellèctus. Ano XVI, n. 1, 2017. Disponível em: <https://www.epublicacoes.uerj.br/index.php/intellectus/article/view/25337/21482>. Acesso em: 
19/11/20.

OLIVEIRA, S. G. Entrevista remota realizada por Cleidionice Pereira dos Santos em 19 de outubro de 2020, em Montes Claros (MG).

PORTELLO, F; BRITES, F. Verdade $\mathbf{x}$ mentira: a ameaça das fakenews nas eleições de 2018 no Brasil. 2018. Disponível em: <file://C:/Users/ACER/AppData/Local/ WhatsApp/app-0.4.2088/resources/app.asar/index.html\#>. Acesso em: 10/04/20.

RICCI, R. Entrevista remota realizada por Cleidionice Pereira dos Santos em 17 de outubro de 2020, em Montes Claros (MG).

Sobre a relação com a pobreza. 2020. Disponível em: <https://ecofranbr. org/sobre-a-relacao-com-a-pobreza/>. Acesso em: 28/09/20.

RODRIGUES, L. Entrevista remota realizada por Cleidionice Pereira dos Santos em 17 de outubro de 2020, em Montes Claros (MG).

SANTOS, M. Histórias de vida na grande reportagem: um encontro entre jornalismo e história oral. Comunicação \& Informação, v. 12, n.2, p. 21-32, jul./dez. 2009. Disponível em: <https://revistas.ufg.br/ci/article/view/12266/8129>. Acesso em: 28/09/20.

SOARES, M. S. G. Entrevista remota realizada por Cleidionice Pereira dos Santos em 20 de outubro de 2020, em Montes Claros (MG).

SOUZA, E. F. Entrevista remota realizada por Cleidionice Pereira os Santos em 13 de outubro de 2020, em Montes Claros (MG).

STEDILE, J. P. II Encontro Mundial dos Movimentos Populares com o Papa Francisco. Documentos. Santa Cruz de la Sierra, Bolívia. 2015. Disponível em: <http://fmclimaticas.org.br/wp-content/uploads/2015/08/II-Encontro-MundialMov-Pop-com-Papa-Francisco-21ago15-documentos.pdf>. Acesso em: 30/08/20. 